\title{
Die Heilmittel der Serenissima
}

\author{
Erhard Taverna
}

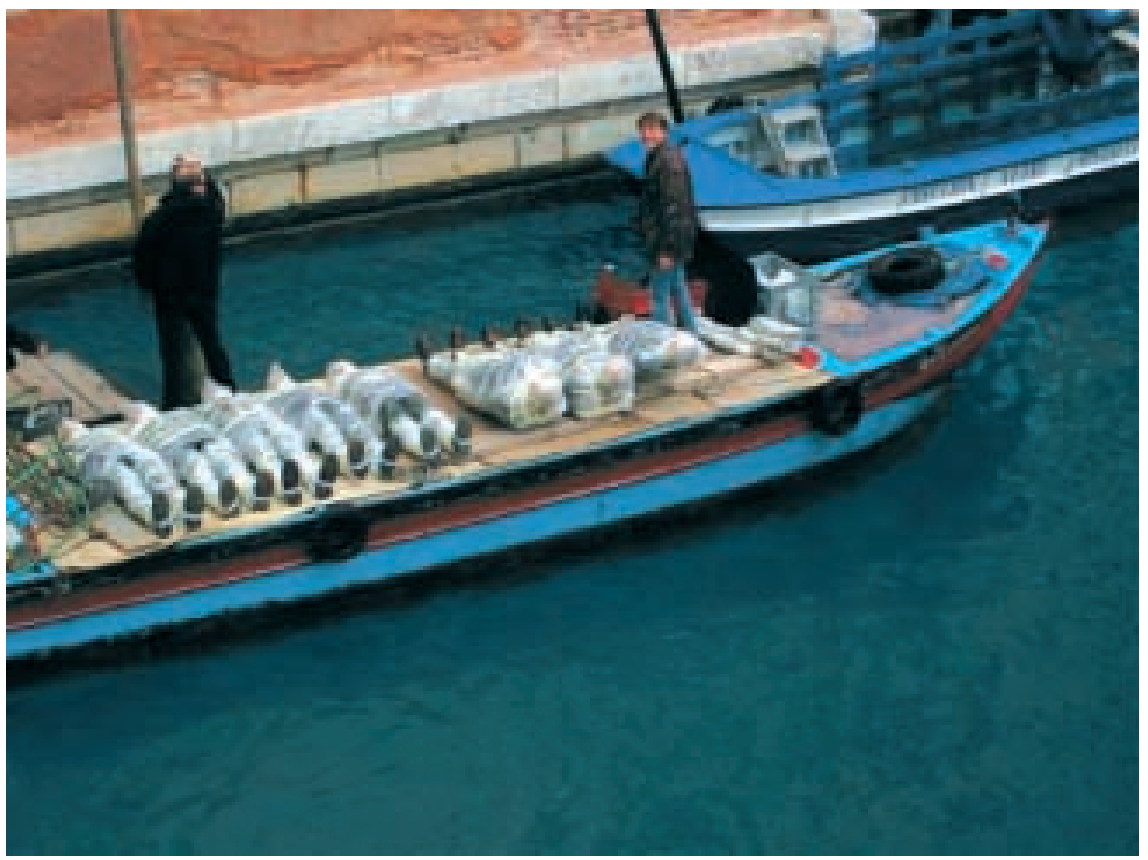

stadt ist eine Mittelmeermacht, führend im Buchdruck, in der Glasmanufaktur, in der Herstellung von Seide- und Baumwollgewebe, im Schiffsbau, im Kanonengiessen, in der Fabrikation von Zucker und Farben, in allen Künsten der Renaissance. Wie in jeder Goldgräberstadt gedeihen auch hier Luxus und Genuss. Auf rund 100000 Einwohner gehen mehr als 12000 Prostituierte ihrem Gewerbe nach. Noch heute lautet ein venezianisches Motto: «messetta, bassetta e donetta», morgens eine kleine Messe, mittags ein Spielchen, abends eine hübsche Frau. In den öffentlichen Thermen treffen sich alle Gesellschaftsschichten. Die damalige Auffassung des Badeortes, der «stufa», kommt dem heutigen Wellnesskonzept sehr nahe, denn sie kombiniert Hygiene mit Wohlgefühl und Gesundheit, nur damals weit üppiger, sinnenfreudiger und ausschweifender.

1495 beschreiben venezianische Militärärzte erstmals die Symptome der neuen Krankheit aus der von Kolumbus entdeckten Welt. Girolamo Francastores Werk «Syphilis sive de morbo gallico libri tres» wird zum Verkaufsschlager seiner Epoche. In Unkenntnis der Spirochäten erfindet er den Mythos von Prinz Sifilo, den der beleidigte Sonnengott mit der Seuche bestraft. Auf die Herausforderungen der Epidemien wie Pest, Syphilis, Cholera und Pocken reagiert der «Consiglio dei Dieci», die höchste Exekutive der Republik, mit einem Konzept, das medizinische, bauliche und gesetzgeberische Massnahmen vereinigt, eine Sicht, die Politik, Religion und Wissenschaft optimal verquickt.

Dem physischen Körper wendet sich die arabisch beeinflusste Medizin zu. Die Empfehlungen Galens und Avicennas werden durch anatomische Beobachtungen auf dem Schlachtfeld, im Sektionssaal und in den öffentlichen Bädern ergänzt. Quecksilber und Guajakholz sind die Mittel der Wahl gegen die Lues, ergänzt durch Diäten der Säftelehre und das Vermeiden der schädlichen Miasmen von Pestilenz und verdorbener Luft. Die modernen Giftmülldeponien der Chemiefabriken von Porto Marghera haben inzwischen die antike Lehre unfreiwillig aktualisiert. Falloppio erfindet ein Präservativ, das der Venezianer Giacomo Casanova als «redingotes anglaises» lobend in seinen Memoiren erwähnt. Irrtümlich wird der Analverkehr empfohlen, in 


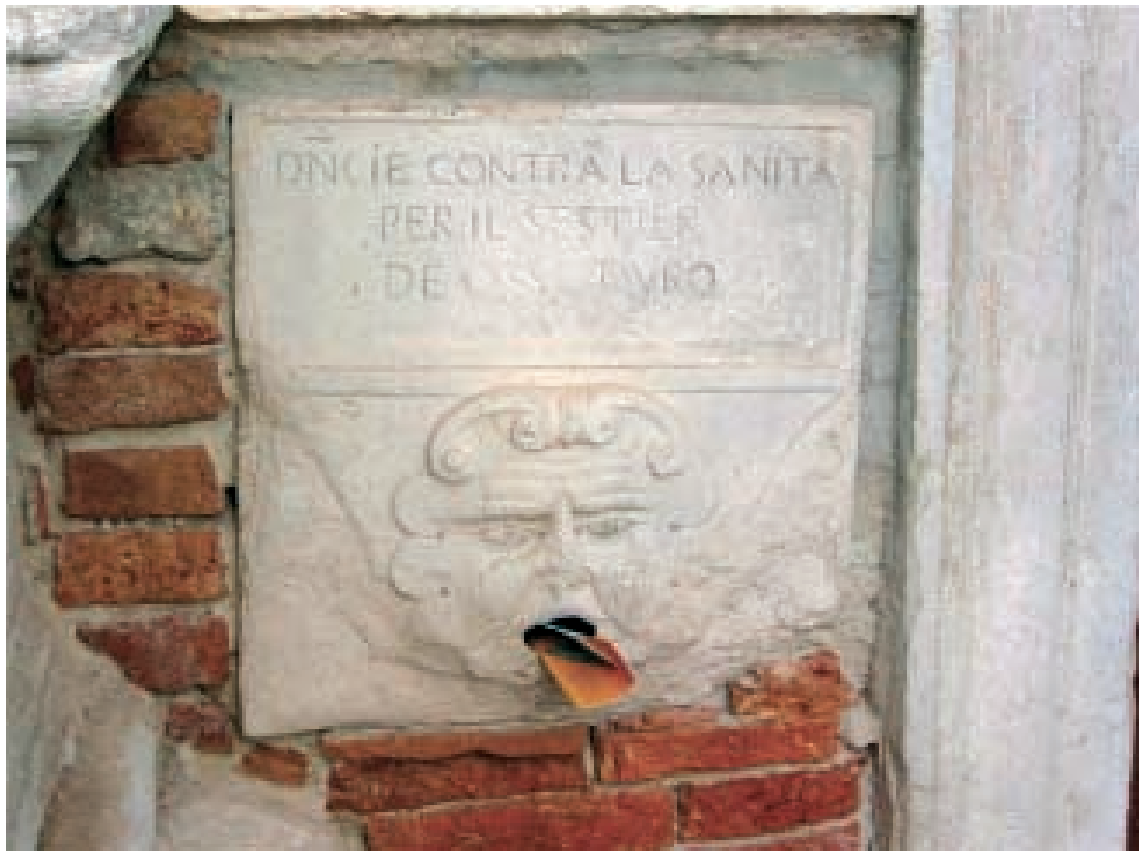

der falschen Annahme, dass eine Ansteckung derart zu vermeiden sei. Viel mehr als Astrologie und Trost ist sonst von der Medizin nicht zu haben. Zum Glück geht die Virulenz der Krankheit über die Jahrzehnte spontan zurück.

Das zweite Konzept vom sozialen Körper greift da schon besser. Die Kanzleien der Dogen verfassen Gesetze und Vorschriften. Der Versuch, die Prostitution auf bestimmte Quartiere zu beschränken, scheitert wie in allen grossen Städten der Gegenwart. Hinter der Basilica dei SS. Giovanni e Paolo entstehen Notfallspitäler. Der «Magistrato dalla sanità» verfolgt eine rigorose Isolationspolitik: ab auf eine der vielen Laguneninseln oder Zwangsbehandlung. Während er wirksam die Repression der Kranken und Armen organisiert, überlässt er die Pflege des einzelnen den Ärzten, den Bruderschaften der «scuole» und der Kirche. Das architektonische Erbe der sanitarischen Massnahmen prägt das Stadtbild bis heute. Die Prävention brauchte Informanten. In jedem Quartier gab es die «Löwenmäuler», deren geöffnete Münder die Zettel der anonymen Denunzianten verschluckten. Am Spitzelsystem der damaligen venezianischen Sanitätspolizei könnte sich heute New York orientieren, wenn die Gesundheitsbehörde Razzien auf versteckte
Aschenbecher organisiert. Diese Topographie der Lazarette, Spitäler, Hospize, Schulen und Gefängnisse verwandelte die folgenden Jahrhunderte zur Touristenattraktion der Konservatorien, Hotels und Kunstgalerien.

Das Konzept vom mystischen Körper medikalisierte in einem gewissen Sinne die Malerei und die Kirche. Der epidemische Tod förderte die emotionale Katharsis. Er förderte die wundertätigen Bilder, die Prozessionen, den Kirchenbau zur Besänftigung von Gottes Zorn. Tizian malt den gemarterten Laurentius, das sieche, bestrafte Fleisch findet Erlösung im himmlischen Glanz. Lust und Busse inspirieren die Kunst. Vom früh an der Pest verstorbenen, genialen Giorgione (1477-1510), dessen wenige Werke die «Accademia» noch bis zum April 2004 ausstellt, sagte Vasari, dass er "geboren sei, die Frische des lebendigen Fleisches getreu nachzuahmen, denn er genoss ohne Unterlass die Freuden der Liebe und spielte hervorragend die Laute». Seine «Laura», der Akt im Fresko, und die Entblösste in der rätselhaften «Tempesta» verherrlichen den in der Renaissance wiederentdeckten Körper. Der Heiligenkult sucht neue Vorbilder. An die Stelle des schönen, nackten San Sebastiano tritt San Rocco. Rochus, der Pestheilige, dessen Leistenbeule die Symptome lehrt und der sich im Wald verkriecht, um niemanden anzustecken. Für die präventive Belehrung der analphabetischen Kirchgänger ist er geeigneter als der passive Vorgänger. Die soziale Kontrolle der Kirche ergänzt die weitgehenden Vollmachten der Sanitätsbehörden. Wer nicht spätestens nach drei ärztlichen Hausbesuchen eine Beichte ablegt, macht sich strafbar. Wenn der Nachbar will, kann er der Inquisition einen Wink geben, denn dafür sind die zahlreichen Löwenmäuler da.

Nachts, auf dem Deck eines «vaporetto» im Canal Grande, werden die Palazzi zum Weihnachtskalender mit seinen aufgeklappten Fenstern: Am Landesteg des «ardone» schaukeln die leeren Gondeln, und an den verzierten Decken funkeln die Kronleuchter über den Gästen im hell erleuchteten «piano nobile». Die «calli» und «campi» träumen in einer brüchigen Gegenwart. Rilke hat die Stadt ein «Gegengewicht zur Welt» genannt. Die Serenissima wäre für das 21. Jahrhundert eine wunderbare Lektion zum Thema Gleichgewicht. 